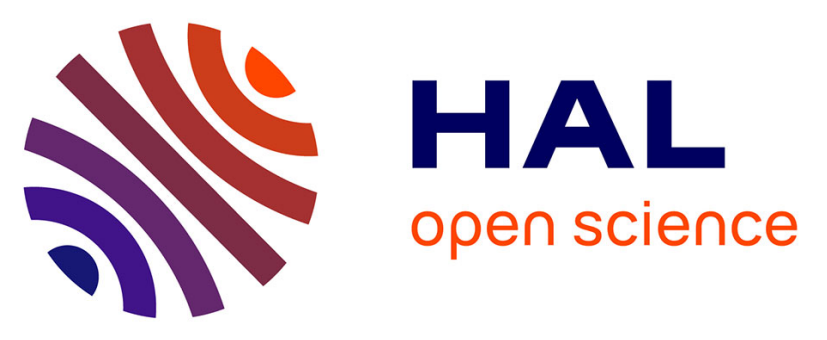

\title{
Atomic Contributions to the Valence Band Photoelectron Spectra of Metal-free, Iron and Manganese Phthalocyanines
}

Ieva Bidermane, I.E. Brumboiu, R. Totani, C. Grazioli, M.N. Shariati-Nilsson, H.C. Herper, O. Eriksson, B. Sanyal, B. Ressel, M. de Simone, et al.

\section{To cite this version:}

Ieva Bidermane, I.E. Brumboiu, R. Totani, C. Grazioli, M.N. Shariati-Nilsson, et al.. Atomic Contributions to the Valence Band Photoelectron Spectra of Metal-free, Iron and Manganese Phthalocyanines. Journal of Electron Spectroscopy and Related Phenomena, 2015, 205, pp.92-97. 10.1016/j.elspec.2015.09.004 . hal-01217182

\section{HAL Id: hal-01217182 \\ https://hal.sorbonne-universite.fr/hal-01217182}

Submitted on 21 Oct 2015

HAL is a multi-disciplinary open access archive for the deposit and dissemination of scientific research documents, whether they are published or not. The documents may come from teaching and research institutions in France or abroad, or from public or private research centers.
L'archive ouverte pluridisciplinaire HAL, est destinée au dépôt et à la diffusion de documents scientifiques de niveau recherche, publiés ou non, émanant des établissements d'enseignement et de recherche français ou étrangers, des laboratoires publics ou privés. 


\section{Atomic Contributions to the Valence Band Photoelectron Spectra of Metal-free, Iron and Manganese Phthalocyanines}

I. Bidermane, ${ }^{1,2, \text { a) }}$ I.E. Brumboiu, ${ }^{1}$ R. Totani, ${ }^{3}$ C. Grazioli, ${ }^{4,5}$ M. N. Shariati-Nilsson, ${ }^{1}$ H. C. Herper, ${ }^{1}$ O. Eriksson, ${ }^{1}$ B. Sanyal, ${ }^{1}$ B. Ressel, ${ }^{6}$ M. de Simone,${ }^{4}$ L. Lozzi, ${ }^{3}$ B. Brena, ${ }^{1}$ and C. Puglia ${ }^{1}$

1) Department of Physics and Astronomy, Uppsala University, Box-516, 75120 Uppsala, Sweden

2) Institut des Nanosciences de Paris, UPMC Univ. Paris 06, CNRS UMR 7588, F-75005, Paris, France

3) Department of Physical and Chemical Sciences, University of L'Aquila, Via Vetoio, I-67010 Coppito, L'Aquila, Italy

4) CNR-IOM, Laboratorio TASC, ss. 14 km. 163.5, Basovizza, 34149 Trieste, Italy

5) Departement of Chemical and Pharmaceutical Sciences, University of Trieste, Italy

6) University of Nova Gorica, Vipavska Cesta 11c, 5270 Ajdovščina, Slovenia

(Dated: 13 September 2015) 
The present work reports a photoelectron spectroscopy study of the low-energy region of the valence band of metal-free phthalocyanine $\left(\mathrm{H}_{2} \mathrm{Pc}\right)$ compared with those of iron phthalocyanine $(\mathrm{FePc})$ and manganese phthalocyanine $(\mathrm{MnPc})$. We have analysed in detail the atomic orbital composition of the valence band both experimentally, by making use of the variation in photoionization cross-sections with photon energy, and theoretically, by means of density functional theory. The atomic character of the Highest Occupied Molecular Orbital (HOMO), reflected on the outermost valence band binding energy region, is different for $\mathrm{MnPc}$ as compared to the other two molecules. The peaks related to the $\mathrm{C} 2 \mathrm{p}$ contributions, result in the $\mathrm{HOMO}$ for $\mathrm{H}_{2} \mathrm{Pc}$ and $\mathrm{FePc}$ and in the HOMO-1 for MnPc as described by the theoretical predictions, in very good agreement with the experimental results. The DFT simulations, discerning the atomic contribution to the density of states, indicate how the central metal atom interacts with the $\mathrm{C}$ and $\mathrm{N}$ atoms of the molecule, giving rise to different partial and total density of states for these three Pc molecules.

a) Electronic mail: ieva.bidermane@physics.uu.se 


\section{INTRODUCTION}

Phthalocyanines (Pc's) are a class of organic compounds widely studied due to the possibility to deposit them in supramolecular architectures suitable for a variety of technological applications. To acquire the ability to design materials with predetermined properties by choosing proper molecular precursors requires understanding of the characteristics of the molecules used as building blocks and how they are modified when deposited in films, as has been well pointed out by Claessens et al. ${ }^{1}$ and de la Torre et al. ${ }^{2}$ in their review articles.

In this work we present a theoretical and experimental valence band (VB) photoelectron spectroscopy (PES) study of the electronic structure of metal-free phthalocyanine $\left(\mathrm{H}_{2} \mathrm{Pc}\right)$, iron phthalocyanine $(\mathrm{FePc})$ and manganese phthalocyanine $(\mathrm{MnPc})$ in multilayer films as well as in the gas phase. We concentrate on the comparison of the occupied valence density of states of these three phthalocyanines and we relate the observed differences to the different metal atom in the molecular central ring. By selecting proper photon energies in the experiment, we can exploit the photoionization cross sections for the photoemission of electrons from different atomic orbitals. In this way, we can disentangle in the experimental spectra the contributions given by the metallic $3 \mathrm{~d}$ electrons from the contributions coming from the organic rings.

Our focus is on the very outermost part of the valence band which determines the electric and magnetic properties of functional materials. Although widely studied, the electronic structure, and in particular the localization of the metallic orbitals in the VB of $3 \mathrm{~d}$ metal Pcs is still under debate since both experimental and theoretical investigations have provided ambiguous outcomes so far, see for example Refs. 3-13. This is a crucial issue for electronic devices, since the character of the outermost molecular orbitals plays a key role in transport related phenomena ${ }^{14}$ : for example a localized $3 \mathrm{~d}$ metallic HOMO or a less localized molecular orbital distributed over the whole molecule would in principle be expected to behave differently ${ }^{14-16}$. In our previous works on $\mathrm{FePc}^{9}$ and $\mathrm{MnPc}^{11}$, we have shown how hybrid DFT can successfully be used to identify the metallic 3d states in the low binding energy region of the valence band, in comparison to PES measurements exploiting the photoionization cross sections. The energy positions of the outermost molecular orbitals could be reproduced with good accuracy by hybrid DFT calculations (B3LYP/DFT).

It has to be observed that for many molecules, the valence band DOS computed by 
means of hybrid DFT may severely differ from the experimental photoelectron spectra ${ }^{17}$. Methods like Gaussian Wave have been used on some molecules including CuPc obtaining important improvements with respect to the hybrid DFT results ${ }^{17}$, but this computation method is rather demanding ${ }^{18}$. Therefore the possibility to employ computationally cheaper methods, like hybrid functionals implemented in a Gaussian basis set description, is still an important option in several cases. The comparison of the metal free $\mathrm{H}_{2} \mathrm{Pc}$ with $\mathrm{FePc}$ and $\mathrm{MnPc}$ highlights the different interactions of the divalent central ion with the organic molecular ring.

As shown by Grobosch et al. ${ }^{6,7}$, the electronic structure of $\mathrm{MnPc}$ differs from the one of other metal Pcs because the HOMO peak in its valence band spectrum is of metallic character. Moreover the 3d electronic states contributing to this VB feature are not highly localized but hybridize with the orbitals of the organic rings, giving to this molecule potentially different electronic transport properties $^{6,7}$.

In general, as we have recently reported ${ }^{11}$, the picture of the electronic structure of metal phthalocyanines can be further complicated: $\mathrm{MnPc}$ can have different electronic configurations in different types of samples, as we have seen for the gas phase with respect to a thick film. While for the thick film a single electronic structure could reproduce the energy distribution of the $\mathrm{MnPc}$ metallic states, in the gas phase, at least two different electronic configurations were needed. In this work we have further investigated these results by studying the symmetry and the hybridization of the outer molecular orbitals comparing $\mathrm{H}_{2} \mathrm{Pc}, \mathrm{MnPc}$ and $\mathrm{FePc}$ molecular films. We provide a detailed determination of the orbital composition of the HOMO and HOMO-1 of $\mathrm{H}_{2} \mathrm{Pc}$, FePc and MnPc by comparing hybrid DFT calculations to PE spectra for thick molecular films. This gives in addition insight into the different hybridization of the metal states with the organic rings for the two metal phthalocyanines.

\section{EXPERIMENTAL DETAILS}

This work includes VB PES measurements of both films and gas phase of phthalocyanines. The $\mathrm{H}_{2} \mathrm{Pc}$ (98\% dye content), FePc molecules (90\% dye content) and MnPc (95\% dye content) molecules were purchased from Sigma-Aldrich. The molecules have been carefully outgassed before all depositions and gas phase measurements. For thick film investigations, 
either a $\mathrm{Au}(111)$ single crystal (in the case of $\mathrm{H}_{2} \mathrm{Pc}$ and $\mathrm{FePc}$ ), purchased from Surface Preparation Laboratory (SPL) or a gold on mica (in the case of MnPc) substrate were used. In the case of the single crystal substrate, a clean $\mathrm{Au}(111)$ surface was obtained by cycles of $\mathrm{Ar}^{+}$ion beam sputtering $(900 \mathrm{eV})$ for 20 minutes, followed by annealing at $\approx 550^{\circ} \mathrm{C}$ for about 2 hours. For the gold/mica substrate (purchased from George Albert Physical Vapor Disposition), the $300 \mathrm{~nm}$ thick layer of gold epitaxially grown on mica, was cleaned by cycles of sputtering and annealing (at $445^{\circ} \mathrm{C}$ ) in order to get a clean and reconstructed $\mathrm{Au}(111)$ surface. The cleanliness of all the surfaces was checked by PES.

The VB photoemission measurements of $\mathrm{H}_{2} \mathrm{Pc}$ films on $\mathrm{Au}(111)(h \nu=130 \mathrm{eV})$ have been performed at the undulator-based ${ }^{19}$ beamline 1511 at MAX-lab, the national synchrotron radiation facility in Lund, Sweden. The surface end-station of the beamline (at the time of our experiments) consisted of an analysis chamber and a preparation chamber, with base pressures of $8 \times 10^{-11}$ and $5 \times 10^{-10} \mathrm{mbar}$, respectively. The analysis chamber was equipped with a Scienta R4000 hemispherical electron analyzer, which could be rotated around the photon beam axis. The molecules have been deposited, in situ, onto the samples in an evaporation chamber under UHV conditions, using a home-built evaporator positioned a few centimeters away from the substrate. The evaporator consisted of a quartz glass tube with a diameter of about $5 \mathrm{~mm}$ with a heating tungsten wire twisted around. All measurements were performed with the sample at room temperature (RT), with photon energy of $130 \mathrm{eV}$ and an overall resolution of about $20 \mathrm{meV}$. The binding energy (BE) scale of the $\mathrm{H}_{2} \mathrm{Pc} V B$ spectra was calibrated by measuring the Fermi edge of the Au substrate and/or $\mathrm{Au} 4 \mathrm{f} \mathrm{PE}$ spectrum (at $84.0 \mathrm{eV} \mathrm{BE}$ ) keeping the experimental settings. FePc and $\mathrm{H}_{2} \mathrm{Pc}$ films deposited by thermal evaporation on the $\mathrm{Au}(111)$ crystal and film of $\mathrm{MnPc}$ on a $\mathrm{Au} /$ mica substrate have also been investigated by XPS using a monochromatized $\mathrm{Al} \mathrm{K}_{\alpha}$ source $(1486.7 \mathrm{eV})$ and Ultra-violet photoelectron spectroscopy (UPS) with a He discharge lamp (21.2 eV) and a hemispherical analyzer at home laboratory at the University of L'Aquila, Italy. For the film thicknesses studied in this work, no signal from the Au $4 \mathrm{f}$ peaks was detected by XPS. The binding energy (BE) scale was calibrated considering the Au Fermi edge and the $\mathrm{Au}$ 4f core level peaks position $\left(\mathrm{Au} 4 \mathrm{f}_{7 / 2}\right.$ at $\left.84 \mathrm{eV}\right)$. The resolution of the presented valence photoemission spectra is $300 \mathrm{meV}$ for photon energy of $1486.7 \mathrm{eV}$ and $150 \mathrm{meV}$ for photon energy of $21.2 \mathrm{eV}$.

The experimental details in acquiring the gas-phase data of $\mathrm{FePc}$ and $\mathrm{MnPc}$ are presented 
in details in the study by Brena et al. ${ }^{9}$ and Brumboiu et al. ${ }^{11}$. The photoelectron spectroscopy (PES) measurements have been performed at the Gas Phase beamline ${ }^{20}$ at the Elettra synchrotron, in Trieste, Italy. The valence spectra of gas phase MnPc were taken using a VG $150 \mathrm{~mm}$ hemispherical electron energy analyzer, equipped with six channel electron multipliers mounted at the magic angle $\left(54.7^{\circ}\right)$ with respect to the E vector of the linearly polarized incident light ${ }^{21}$. Valence data of gas phase $\mathrm{H}_{2} \mathrm{Pc}$ and $\mathrm{FePc}$ presented in this work were instead measured with a SES-200 electron analyzer ${ }^{22}$ also mounted at the magic angle. The molecular samples were evaporated using a custom built resistively heated furnace. The gas phase PE spectra were checked during heating procedure, comparing them to spectra for thick layers obtained by Kraus et al. ${ }^{8,23}$ for $\mathrm{MnPc}$, while for FePc they were compared to He I spectrum obtained by Berkowitz ${ }^{24}$. Calibration of the energy scale was done introducing He (vertical ionization energy, VIE=24.59 eV) into the ionization chamber and by traces of vaporized water $\left(\mathrm{H}_{2} \mathrm{O}, \mathrm{VIE}=12.26 \mathrm{eV}\right)^{25}$ found in the system. The photon energies used for valence band measurements were $110 \mathrm{eV}$ for $\mathrm{H}_{2} \mathrm{Pc}$ and FePc spectra and $100 \mathrm{eV}$ for $\mathrm{MnPc}$ valence band spectrum, all with spectral resolution of about $200 \mathrm{meV}$.

\section{COMPUTATIONAL METHODS}

The geometry of $\mathrm{H}_{2} \mathrm{Pc}$ and of the two transition metal Pcs was optimized by means of density functional theory (DFT) using the Gaussian 09 version D.01 quantum chemistry software $^{26}$. The functional used was HSE06 $6^{27-33}$ in combination with the 6-31G(dp) basis set $^{34}$ for the $\mathrm{C}, \mathrm{N}$ and $\mathrm{H}$ atoms and the cc-pVTZ basis set ${ }^{35}$ for $\mathrm{Mn}$ and Fe. We have chosen the range-separated hybrid functional HSE06 $6^{27-33}$, which has been shown to improve the description of magnetic molecular systems in general ${ }^{36}$. Moreover, this functional was able to provide a good agreement with experimental valence band data in the case of $\mathrm{MnPc}$, especially for occupied states at high binding energies ${ }^{37}$.

A $\mathrm{D}_{2 h}$ initial geometry was used for $\mathrm{H}_{2} \mathrm{Pc}$, while for $\mathrm{MnPc}$ and $\mathrm{FePc}$ the starting point geometry was $D_{4 h}$. Both transition metal phtalocyanines relaxed to a $D_{2 h}$ point group. The optimized geometry was used to determine the electronic structure alongside the contribution of each particular type of atomic orbital (AO) to the valence band molecular orbitals. Similarly to previous studies ${ }^{9,11}$, the population analysis was performed using the $c^{2} \operatorname{method}^{38,39}$. The $c^{2}$ coefficients were used to obtain the total and partial densities of 
states (DOS). The bar graphs, corresponding to the discrete molecular energy levels, were broadened using Gaussian functions with a constant full width at half maximum (FWHM) of $0.4 \mathrm{eV}$ (unless stated otherwise) in order to facilitate the comparison with experiment. The atomic origins of particular peaks were obtained by comparing the total DOS to the C 2p, N 2p, C 2s, N 2s and metal (M) 3d partial contributions.

The spectra corresponding to different photon energies $(21.2 \mathrm{eV}, 130 \mathrm{eV}$ and $1486.7 \mathrm{eV})$ were obtained by multiplying each partial DOS with its atomic photoionization cross-section at the specific energy ${ }^{40-43}$. The total spectrum was obtained by summing up the atomic contributions and by adding a Gaussian broadening of variable FWHM. The initial FWHM of 0.2 $\mathrm{eV}$ was linearly increased to $2.0 \mathrm{eV}$ in the interval $-5.0 \mathrm{eV}-15.0 \mathrm{eV}$ and then kept constant.

\section{RESULTS AND DISCUSSION}

Density functional theory (DFT) calculations of total and partial DOS of a single $\mathrm{H}_{2} \mathrm{Pc}$ molecule together with an experimental valence-band spectrum taken with a photon energy of $130 \mathrm{eV}$ of a thick film of $\mathrm{H}_{2} \mathrm{Pc} / \mathrm{Au}(111)$ are shown in Figure 1. The energy scale of the theoretical calculations has been aligned to the experimental spectrum by a shift of -3.5 $\mathrm{eV}$. The introduced shift of the theoretical data accounts mostly for the work function of the sample and the relaxation processes that have not been included in theoretical calculations. The molecular orbital energies obtained by HSE/DFT are able to reproduce the experimental PES peaks. The PE valence spectrum contains several features associated with contributions of different molecular orbitals which are disentangled by the partial DOS calculations presented in Figure 1. The peaks in the experimental spectrum have been labelled from $\mathrm{A}$ to $\mathrm{H}$ as in Ref. 44. Peak $\mathrm{A}$ is related to the $\mathrm{HOMO}$ and is located at $1.5 \mathrm{eV}$ binding energy (BE). In a previous theoretical study of a thick film of $\mathrm{H}_{2} \mathrm{Pc}$ on conductive glass ${ }^{45}$, it was found that the HOMO peak has a $\pi$ character, a $a_{u}$ symmetry and is formed by C 2p orbitals. From the present theoretical analysis of the partial DOS, we furthermore find that the most pronounced peak $\mathrm{B}$, located at $3.9 \mathrm{eV} \mathrm{BE}$, is due to contributions of p-type orbitals of both carbon and nitrogen atoms and a small contribution of s-type orbitals of nitrogen atoms. Peak $\mathrm{C}$ is a low-intensity peak mainly formed by contributions of both sand p-type orbitals of $\mathrm{N}$ atoms together with a small contribution of $\mathrm{C} 2 \mathrm{p}$ orbitals. Peak $\mathrm{D}$ is mainly related to $\mathrm{C} 2 \mathrm{p}$ orbitals with minor contributions from $\mathrm{N} 2 \mathrm{p}$ and $\mathrm{C} 2 \mathrm{~s}$ states. 


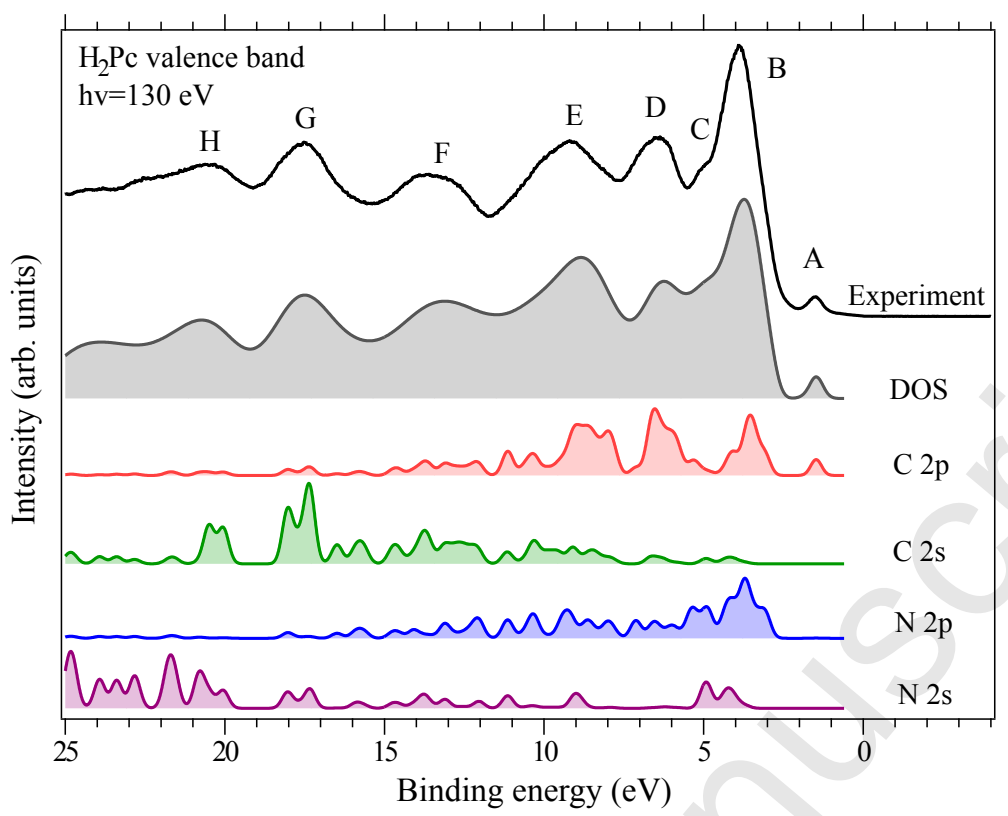

FIG. 1: (Color online) Experimental spectrum of a thick film of $\mathrm{H}_{2} \mathrm{Pc} / \mathrm{Au}(111)$ and DFT calculations of total and partial DOS of a single $\mathrm{H}_{2} \mathrm{Pc}$ molecule. The initial FWHM used for the Gaussian broadening of the calculated total DOS is in this case $0.5 \mathrm{eV}$. The linear increase in FWHM was performed as stated in the Computational Methods section.

Peak E originates mainly in C 2p orbitals with C 2s, N 2s and N 2p states contributing to a small extent as well. Finally, peaks F and G are instead mainly formed out of contributions from $\mathrm{C}$ and $\mathrm{N}$ s-type orbitals.

Figure 2 shows a comparison of the HOMO valence energy region of the three phthalocyanines (FePc, MnPc and $\mathrm{H}_{2} \mathrm{Pc}$ ) in gas phase. Spectra are taken with photon energy of 110 $\mathrm{eV}$ for $\mathrm{H}_{2} \mathrm{Pc}$ and $\mathrm{FePc}$ and $100 \mathrm{eV}$ for $\mathrm{MnPc}$. In these gas phase spectra the peaks with mostly $\mathrm{C} 2 \mathrm{p}$ character, $\mathrm{HOMO}$ of $\mathrm{FePc}$ and $\mathrm{H}_{2} \mathrm{Pc}$, and $\mathrm{HOMO}-1$ for $\mathrm{MnPc}$, are at the same BE $(6.4 \mathrm{eV})$. This result is also confirmed by our theoretical calculations (Figure 4) showing that the $\mathrm{C} 2 \mathrm{p}$-derived peak in the outermost valence is expected at the same BE for all three phthalocyanines. This result could be considered anticipated as shown in previous work by Grobosch et al. ${ }^{6}$, where the authors stated that this feature, due to the ligand HOMO, wouldn't hybridize with any metal 3d states being of alu symmetry. The energy position of the MnPc HOMO (with Mn 3d character $^{11}$ ) is instead expected at lower BE (at $5.9 \mathrm{eV}$, hence resulting in an energy difference $\Delta E_{b}=0.5 \mathrm{eV}$ ), in very good agreement with what is observed experimentally and reported in Figure 2. 

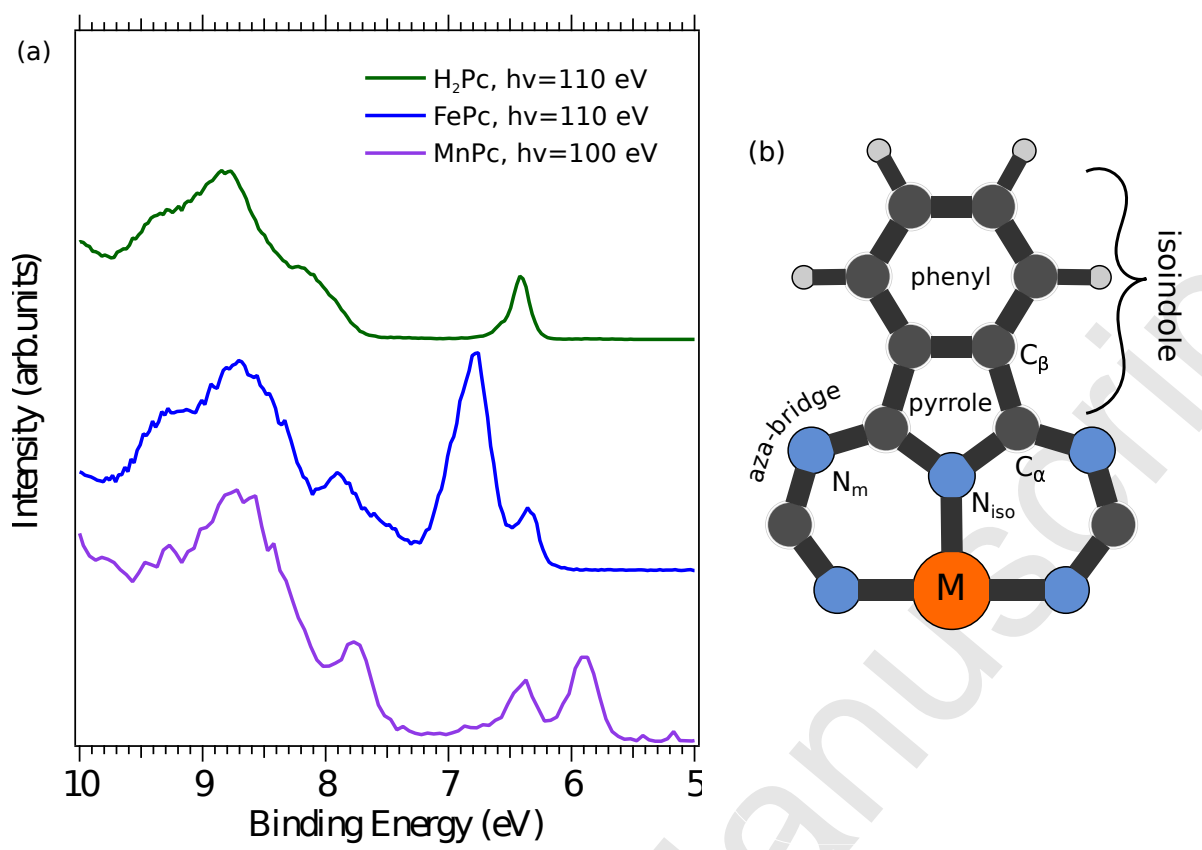

FIG. 2: (Color online) Valence band experimental spectra of gas phase $\mathrm{H}_{2} \mathrm{Pc}(110 \mathrm{eV})$, $\mathrm{FePc}(\mathrm{hv}=110 \mathrm{eV})$ and $\mathrm{MnPc}(\mathrm{hv}=100 \mathrm{eV})(\mathrm{a})$. Fragment of the metal phthalocyanine molecular structure displaying the notations used in this article (b).

In Figure 3 we directly compare the valence band $\mathrm{PE}$ spectra of $\mathrm{H}_{2} \mathrm{Pc}, \mathrm{MnPc}$ and $\mathrm{FePc}$ molecular films, taken with photon energies of $1486.7 \mathrm{eV}$ (a) and $21.2 \mathrm{eV}$ (b). The experimental spectra are compared with the respective DFT total DOS (dotted lines). The DFT calculated spectra have been shifted in energy to match the HOMO level of the respective experimental spectrum, giving a shift of $-3.2 \mathrm{eV}$ for $\mathrm{H}_{2} \mathrm{Pc}$ and of $-3.6 \mathrm{eV}$ for both metal Pcs in case of experiments performed with photon energy of $1486.7 \mathrm{eV}$ and $-3.4 \mathrm{eV}$ for $\mathrm{H}_{2} \mathrm{Pc}$ and -3.5 for both metal Pcs in case of experiments performed with photon energy of $21.2 \mathrm{eV}$. Due to the different cross-section sensitivity, the spectra taken with He I (21.2 eV) photon energy, show mostly the contribution of the C 2p and N 2p states, whereas the spectra taken with $\mathrm{Al} \mathrm{K}_{\alpha}(1486.7 \mathrm{eV})$ photon energy enhance the metal atom contributions. In fact, at the photon energy of $21.2 \mathrm{eV}$, the photoionization cross-sections of $\mathrm{C} 2 \mathrm{p}$ and $\mathrm{N} 2 \mathrm{p}$ are of 6.13 and 9.66 Mbarn being in the same order of magnitude of the cross-section of Fe 3d (which is $4.82 \mathrm{Mbarn}$ ) and of Mn 3d (which is $5.34 \mathrm{Mbarn}$ ). On the contrary, at 1486.7 $\mathrm{eV}$, the contributions to the PES of the $3 \mathrm{~d}$ metallic states are respectively 100 and 25 times higher than the contributions of the $\mathrm{C}$ and $\mathrm{N} 2 \mathrm{p}$ of the $\mathrm{Pc}$ rings since the respective cross 
sections become $2.34 \cdot 10^{-3}$ (Fe 3d), $1.44 \cdot 10^{-3}$ (Mn 3d), 2.14 $10^{-5}$ (C 2p) and $8.85 \cdot 10^{-5}$ Mbarn (N 2p). The latter measurements, therefore, allow one to get a detailed picture of the energy position in the spectra of the Fe and Mn 3d energy levels. The agreement between the experimental and the theoretical results is very satisfying in both cases. It should be noted here that in the experimental spectra, the background contribution has not been subtracted, which naturally causes a higher intensity at higher binding energies. This is in particular the case for spectra taken with the He I light source. In Figure 4a it is evident that the HOMO (FePc) and HOMO-1 (MnPc) spectral features at $1.7 \mathrm{eV}$ and $0.8 \mathrm{eV}$ binding energies respectively are formed by a hybridization of $3 \mathrm{~d}$ metal and organic states of the molecule. In part (c) of Figure 3 the $\mathrm{HOMO}$ of $\mathrm{H}_{2} \mathrm{Pc}$ is presented alongside the $\mathrm{HOMO}$ and HOMO-1 orbitals of the two metal phtalocyanine molecules. The HOMO of MnPc is situated at lower binding energy $(0.5 \mathrm{eV})$ and contains both $\mathrm{C} 2 \mathrm{p}$ and $\mathrm{Mn} 3 \mathrm{~d}$ contributions. The highest occupied molecular orbital (HOMO) of FePc and $\mathrm{H}_{2} \mathrm{Pc}$ alongside the HOMO-1 of $\mathrm{MnPc}$, all situated at approximately $1.5 \mathrm{eV}$ BE, have exclusively $\mathrm{C} 2 \mathrm{p}$ character. The atoms contributing the most to these orbitals are the pyrrole carbons (denoted $\mathrm{C}_{\alpha}$ in Figure $2 \mathrm{~b}$ ), which are directly bonded to the isoindole nitrogen atoms $\left(\mathrm{N}_{\text {iso }}\right)$. The carbons from the phenyl rings contribute to some extent, whereas the $\mathrm{C}_{\beta}$ pyrrole atoms (Fig. 2b) give only a very small contribution (see also Fig. 1 in the Supplementary Information).

In more detail, the HOMO peak of the $\mathrm{MnPc} V B$ spectrum is formed from the $2 \mathrm{p}$ levels of pyrrole carbon atoms (which are directly bound to Mn atom) in combination with the Mn $\left(\mathrm{d}_{x z}, \mathrm{~d}_{y z}\right)$ orbitals. Similarly, the FePc HOMO-1 is related to the metal $\left(\mathrm{d}_{x z}, \mathrm{~d}_{y z}\right)$ orbitals with a small contribution from $\mathrm{C} 2 \mathrm{p}$ levels. The $2 \mathrm{p}$ character of this $\mathrm{MO}$ is reduced as compared to the MnPc HOMO. The calculated electronic configurations of the two metal phthalocyanines are ${ }^{4} \mathrm{E}_{g}(\mathrm{MnPc})\left(\mathrm{d}_{\pi}^{3} \mathrm{~d}_{x y}^{1} \mathrm{~d}_{z^{2}}^{1}\right)$ and ${ }^{3} \mathrm{E}_{g}(\mathrm{FePc})\left(\mathrm{d}_{\pi}^{3} \mathrm{~d}_{x y}^{2} \mathrm{~d}_{z^{2}}^{1}\right)$. The difference between $\mathrm{MnPc}$ and $\mathrm{FePc}$ implies essentially the presence of one additional electron in FePc alongside an increase in the $\mathrm{Z}$ number of the central metal by one. This additional electron

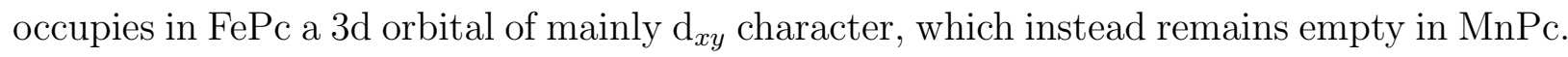
The Fe $\mathrm{d}_{x y}$ orbital has a higher BE with respect to the HOMO-1 of FePc which has a $\left(\mathrm{d}_{x z}\right.$, $\mathrm{d}_{y z}$ ) character. Moreover, the first peak with metal 3d contributions in FePc (the HOMO-1 peak) is located at higher $\mathrm{BE}$ when compared to the same peak in $\mathrm{MnPc}$ (HOMO). This is explained by the higher effective charge of the Fe atom as compared to the $\mathrm{Mn}^{46}$. In this electronic configuration, and in this specific type of sample (thick film) where $\mathrm{MnPc}$ 

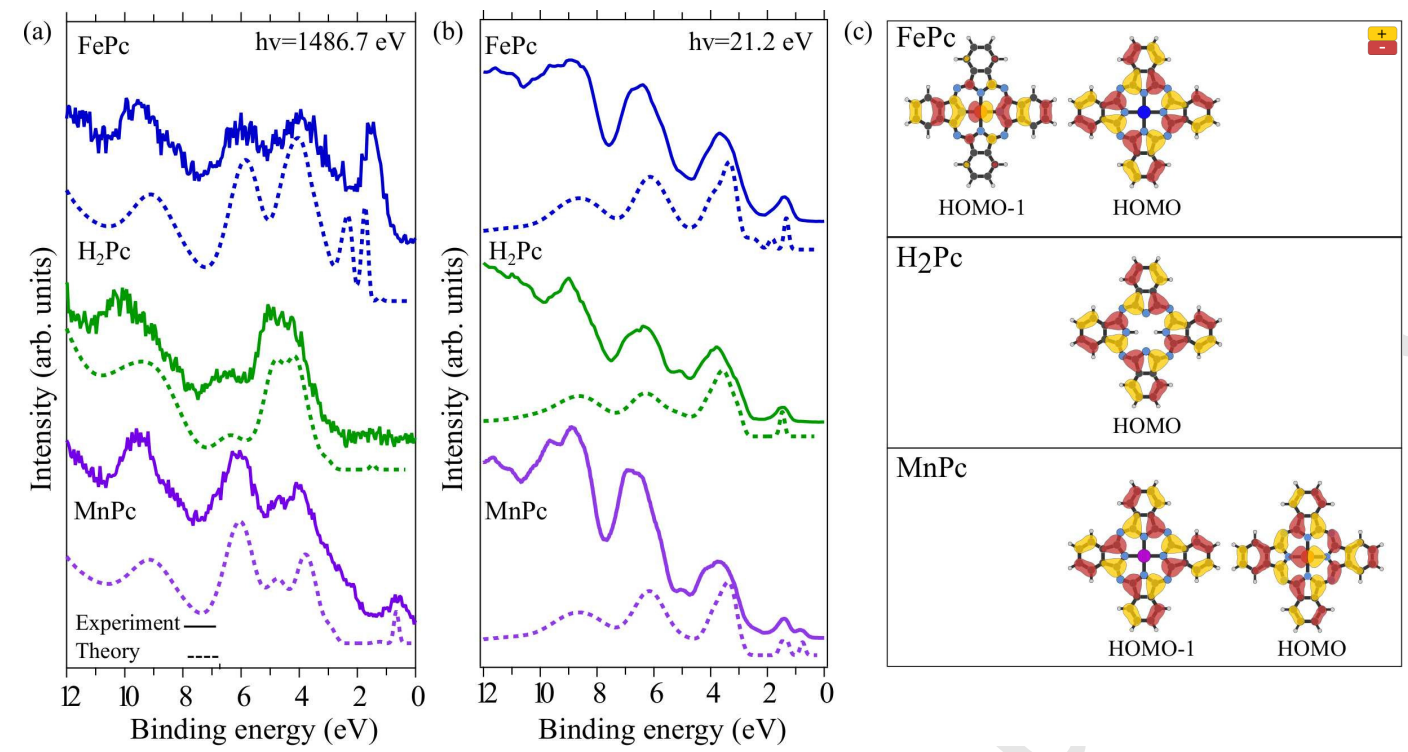

FIG. 3: (Color online) Experimental PES results of valence band region for $\mathrm{H}_{2} \mathrm{Pc}, \mathrm{FePc}$ and $\mathrm{MnPc}$ films on $\mathrm{Au}(111)$ for photon energies of $1486.7 \mathrm{eV}$ (a, solid lines) and $21.2 \mathrm{eV}$ (b, solid lines) together with single molecule DFT simulations of $\mathrm{H}_{2} \mathrm{Pc}, \mathrm{FePc}$ and $\mathrm{MnPc}$ spectra modified according to the cross-section for excitation energies of $1486.7 \mathrm{eV}$ (a, dotted lines) and $21.2 \mathrm{eV}$ (b, dotted lines). The uppermost valence band molecular orbitals are presented alongside (c). Note that the background has not been subtracted from the experimental spectra.

assumes mainly a ${ }^{4} \mathrm{E}_{g}$ configuration ${ }^{11}$, the lowest binding energy $\mathrm{MnPc}$ peak has $\mathrm{e}_{g}$ character composed by a hybridization of $\mathrm{d}_{x z}$ or $\mathrm{d}_{y z}$ with $\mathrm{C} 2 \mathrm{p}$ and $\mathrm{N} 2 \mathrm{p}$ (the $\mathrm{N} 2 \mathrm{p}$ contribution is quite small - from Fig. 4c) orbitals, as was experimentally predicted for example in Ref. 7, 47, and 48. In FePc the orbital with the lowest BE is of $\pi$ character formed mostly by $\mathrm{C} 2 \mathrm{p}$ orbitals, whereas the $\mathrm{e}_{g}$ is found at higher BE, being the HOMO-1.

The DFT calculations shown in Figure 4 further clarify the effects of the metallic center on the valence states. The DFT simulations allow disentangling the different atomic orbital contributions to the valence spectra for the three Pcs. By comparing the simulations of the valence data we can see how the metal atom affects the $\mathrm{C} 2 \mathrm{p}$ and $\mathrm{N} 2 \mathrm{p}$ contributions to the total DOS of each molecule, i.e. the molecular structure of a metal phthalocyanine originates from the hybridization (orbital combination) between the $\mathrm{N}$ (mostly N 2p) and C (mostly C 2p) atoms with the central metal atom. Figure 4 (b) and (c) show the same calculations displaying separately the results for $\mathrm{C} 2 \mathrm{p}$ and $\mathrm{N} 2 \mathrm{p}$ for all Pcs. The $\mathrm{C} 2 \mathrm{p}$ partial DOS for 

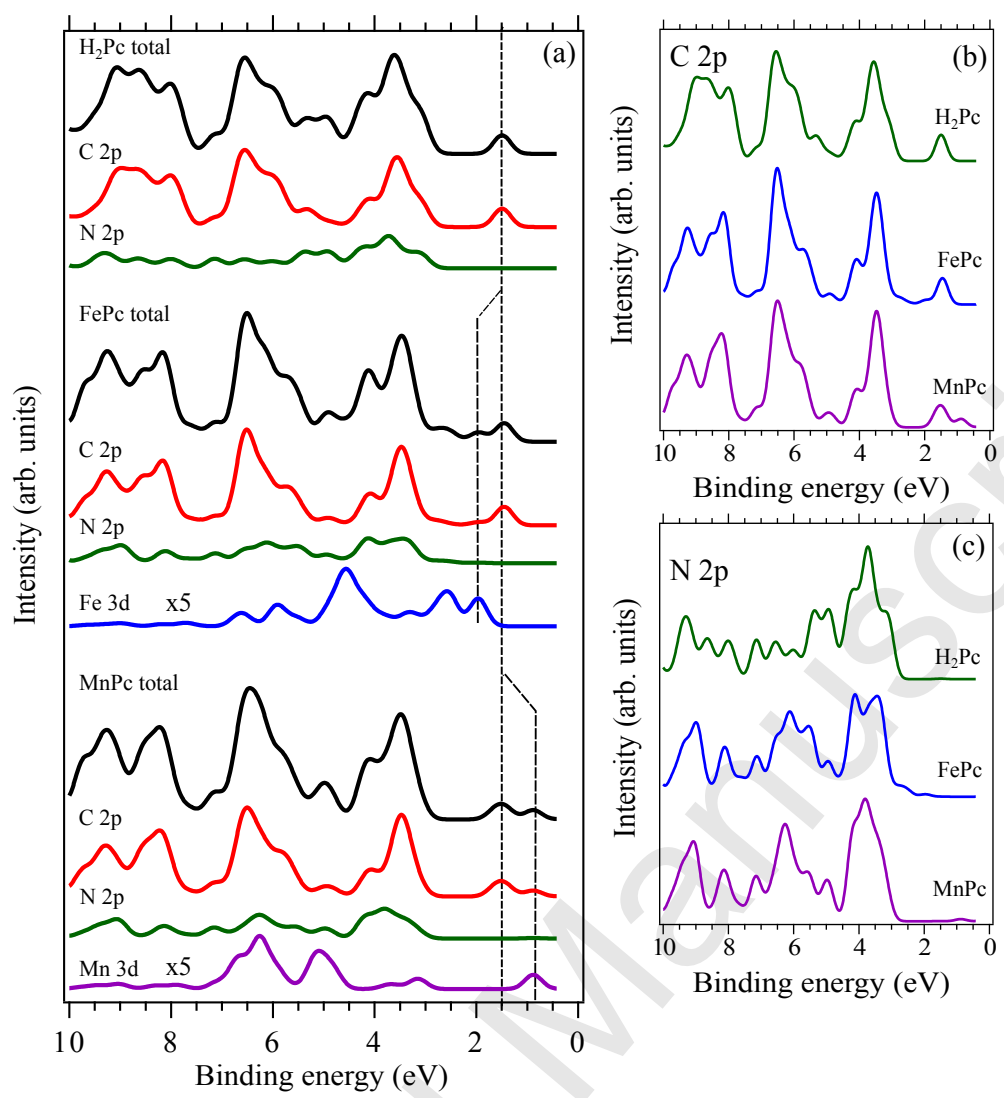

FIG. 4: (Color online) DFT calculated atomic partial DOS of $\mathrm{H}_{2} \mathrm{Pc}, \mathrm{FePc}$ and $\mathrm{MnPc}$ (a).

The comparison between the C $2 \mathrm{p}$ and N $2 \mathrm{p}$ contributions is shown in (b) and (c), respectively. The dashed lines in (a) show the change of HOMO and HOMO-1 peaks for the metal Pcs.

the metal Pcs show a slight change in the spectral shape at the energies of the metal atom contributions, indicating a hybridization of $\mathrm{C} 2 \mathrm{p}$ orbitals with the metal atom. It is mostly seen at lower BE, where the respective metal contribution is stronger - at around $2 \mathrm{eV}$ for $\mathrm{FePc}$ and at around $0.8 \mathrm{eV}$ for $\mathrm{MnPc}$, as a result of the hybridization of the $3 \mathrm{~d}$ Mn levels with the adjacent $\mathrm{N}$ atoms in the $\mathrm{HOMO}$ in $\mathrm{MnPc}$. The contribution to the hybridization at low BE is due to the N 2p states of the pyrrole N, closest to the central metal (see Supplementary Information), while the bridging aza-nitrogens in the MPcs display 2p partial densities of states, which are relatively similar to the $\mathrm{H}_{2} \mathrm{Pc}$ case, and are therefore unaffected by the presence of the metal. 


\section{CONCLUSIONS}

The valence-band $\mathrm{PE}$ spectra of thick films of $\mathrm{H}_{2} \mathrm{Pc} / \mathrm{Au}(111)$ have been interpreted by DFT calculations. The computed partial DOS show different atomic orbital compositions of the spectral features. The analysis of the outer valence spectra of gas phase Pcs showed that the $\mathrm{HOMO}$ of $\mathrm{H}_{2} \mathrm{Pc}$ and FePc coincides in BE with the HOMO-1 peak of the MnPc spectra and is the result of excitations from an $\mathrm{a}_{u}$ orbital with mainly $\mathrm{C} 2 \mathrm{p}$ character. The HOMO of $\mathrm{MnPc}$ results mainly from the $\left(\mathrm{d}_{x z}, \mathrm{~d}_{y z}\right)$ Mn levels, whereas similarly the HOMO-1 of FePc has a strong $\left(\mathrm{d}_{x z}, \mathrm{~d}_{y z}\right)$ character. A closer analysis of these simulations reveals that the electronic structure of the Pc molecules rises from the combination of orbitals of all the atoms in the molecule - carbon, nitrogen and the metal in the molecular center - and that the HOMO and HOMO-1 features depend on the hybridization between the metal atom and mostly C 2 p and N 2p orbitals. It has been shown that by appropriately choosing the Pc molecules with different central metal atoms, one can change the characteristic molecular features (HOMO states and their BE position), thus tuning to potentially different electronic properties of the Pc molecules.

\section{ACKNOWLEDGMENTS}

We acknowledge financial support from the Swedish Research Council (VR), the KAW foundation, Carl Trygger Foundation and the grants for computer time from the Swedish National Infrastructure for Computing (SNIC). We want to thank Dr. M. Coreno and Dr. A. Kivimäki for valuable discussions. The staffs at Elettra and at MAX-Lab, the Italian and Swedish synchrotron radiation facilities respectively, are acknowledged. B.R. acknowledges Italy-Slovenia Cross Border Cooperation Programme 2007-13 support through MODEF project.

\section{REFERENCES}

${ }^{1}$ C. G. Claessens, U. W. E. Hahn, and T. Torres, Chem. Rec. 8, 75 (2008).

${ }^{2}$ G. de la Torre, C. G. Claessens, and T. Torres, Chem. Commun., 2000 (2007).

${ }^{3}$ M.-S. Liao and S. Scheiner, J. of Chem. Phys. 114, 9780 (2001).

${ }^{4}$ J. Wang, Y. Shi, J. Cao, and R. Wu, Appl. Phys. Lett. 94, 122502 (2009). 
${ }^{5}$ N. Marom and L. Kronik, Appl. Phys. A 95, 165 (2009).

${ }^{6}$ M. Grobosch, V. Y. Aristov, O. V. Molodtsova, C. Schmidt, B. P. Doyle, S. Nannarone, and M. Knupfer, J of Phys Chem C 113, 13219 (2009).

${ }^{7}$ M. Grobosch, B. Mahns, C. Loose, R. Friedrich, C. Schmidt, J. Kortus, and M. Knupfer, Chem. Phys. Lett. 505, 122125 (2011).

${ }^{8}$ M. Grobosch, C. Schmidt, R. Kraus, and M. Knupfer, Org. Electron. 11, 1483 (2010).

${ }^{9}$ B. Brena, C. Puglia, M. de Simone, M. Coreno, K. Tarafder, V. Feyer, R. Banerjee, E. Gothelid, B. Sanyal, P. M. Oppeneer, and O. Eriksson, J. Chem. Phys. 134, 74312 (2011).

${ }^{10}$ T. Kroll, R. Kraus, R. Schönfelder, Y. Aristov, V. Molodtsova, P. Hoffmann, and M. Knupfer, J. of Chem. Phys. 137, 054306 (2012).

${ }^{11}$ I. E. Brumboiu, R. Totani, M. de Simone, M. Coreno, C. Grazioli, L. Lozzi, H. C. Herper, B. Sanyal, O. Eriksson, C. Puglia, and B. Brena, J. Phys. Chem. A 118, 927 (2014).

${ }^{12}$ S. Stepanow, A. Lodi Rizzini, C. Krull, J. Kavich, J. C. Cezar, F. Yakhou-Harris, P. M. Sheverdyaeva, P. Moras, C. Carbone, G. Ceballos, A. Mugarza, and P. Gambardella, J. Am. Chem. Soc. 136, 54515459 (2014).

13.

${ }^{14}$ K. Yoshizawa, Acc. Chem. Res. 45, 16121621 (2012).

${ }^{15}$ A. F. Takács, F. Witt, S. Schmaus, T. Balashov, M. Bowen, E. Beaurepaire, and W. Wulfhekel, Phys. Rev. B 78, 233404 (2008).

${ }^{16}$ G. I. Crdenas-Jirn, P. Leon-Plata, D. Cortes-Arriagada, and J. M. Seminario, J. of Phys. Chem. C 115, 1605216062 (2011).

${ }^{17}$ N. Marom, X. Ren, J. E. Moussa, J. R. Chelikowsky, and L. Kronik, Phys. Rev. B 84, 195143 (2011).

${ }^{18}$ D. A. Egger, S. Weissman, S. Refaely-Abramson, S. Sharifzadeh, M. Dauth, R. Baer, S. Kmmel, J. B. Neaton, E. Zojer, and L. Kronik, J. Chem. Theory Comput. 10, 19341952 (2014).

${ }^{19}$ R. Denecke, P. Väterlein, M. Bässler, N. Wassdahl, S. Butorin, A. Nilsson, J. E. Rubensson, J. Nordgren, N. Mårtensson, and R. Nyholm, J. Electron Spectrosc. Relat. Phenom. 101, 971 (1999).

${ }^{20}$ R. Blyth, R. Delaunay, M. Zitnik, J. Krempasky, R. Krempaska, J. Slezak, K. Prince, R. Richter, M. Vondracek, R. Camilloni, L. Avaldi, M. Coreno, G. Stefani, C. Furlani, 
M. de Simone, S. Stranges, and M. Adam, J. Electron Spectrosc. Relat. Phenom. 101, 959 (1999).

${ }^{21}$ R. M. Pinto, A. A. Dias, M. Coreno, M. de Simone, B. M. Giuliano, J. P. Santos, and M. L. Costa, Chem. Phys. Lett. 516, 149 (2011).

${ }^{22}$ N. Mårtensson, P. Balzer, P. Bruhwiler, J. Forsell, A. Nilsson, A. Stenborg, and B. Wannberg, J. Electron. Spectrosc. Relat. Phenom. 70, 117 (1994).

${ }^{23}$ R. Kraus, M. Grobosch, and M. Knupfer, Chem. Phys. Lett. 469, 121 (2009).

${ }^{24}$ J. Berkowitz, J. Chem. Phys. 70, 2819 (1979).

${ }^{25} \mathrm{~K}$. Kimura, Handbook of HeI photoelectron spectra of fundamental organic molecules: ionization energies, ab initio assignments, and valence electronic structure for 200 molecules (Japan Scientific Societies Press, 1981).

${ }^{26}$ M. J. Frisch, G. W. Trucks, H. B. Schlegel, G. E. Scuseria, M. A. Robb, J. R. Cheeseman, G. Scalmani, V. Barone, B. Mennucci, G. A. Petersson, H. Nakatsuji, M. Caricato, X. Li, H. P. Hratchian, A. F. Izmaylov, J. Bloino, G. Zheng, J. L. Sonnenberg, M. Hada, M. Ehara, K. Toyota, R. Fukuda, J. Hasegawa, M. Ishida, T. Nakajima, Y. Honda, O. Kitao, H. Nakai, T. Vreven, J. J. A. Montgomery, J. E. Peralta, F. Ogliaro, M. Bearpark, J. J. Heyd, E. Brothers, K. N. Kudin, V. N. Staroverov, R. Kobayashi, J. Normand, K. Raghavachari, A. Rendell, J. C. Burant, S. S. Iyengar, J. Tomasi, M. Cossi, N. Rega, J. M. Millam, M. Klene, J. E. Knox, J. B. Cross, V. Bakken, C. Adamo, J. Jaramillo, R. Gomperts, R. E. Stratmann, O. Yazyev, A. J. Austin, R. Cammi, C. Pomelli, J. W. Ochterski, R. L. Martin, K. Morokuma, V. G. Zakrzewski, G. A. Voth, P. Salvador, J. J. Dannenberg, S. Dapprich, A. D. Daniels, Ö. Farkas, J. B. Foresman, J. V. Ortiz, J. Cioslowski, and D. J. Fox, "Gaussian09 Revision D.01," Gaussian Inc. Wallingford CT 2009 .

${ }^{27}$ J. Heyd and G. E. Scuseria, J. Chem. Phys. 121, 1187 (2004).

${ }^{28}$ J. Heyd and G. E. Scuseria, J. Chem. Phys. 120, 7274 (2004).

${ }^{29}$ J. Heyd, J. E. Peralta, G. E. Scuseria, and R. L. Martin, J. Chem. Phys. 123, 174101 (2005).

${ }^{30}$ J. Heyd, G. E. Scuseria, and M. Ernzerhof, J. Chem. Phys. 124, 219906 (2006).

${ }^{31}$ A. F. Izmaylov, G. E. Scuseria, and M. J. Frisch, J. Chem. Phys. 125, 104103 (2006).

${ }^{32}$ A. V. Krukau, O. A. Vydrov, A. F. Izmaylov, and G. E. Scuseria, J. Chem. Phys. 125, 224106 (2006). 
${ }^{33}$ T. M. Henderson, A. F. Izmaylov, G. Scalmani, and G. E. Scuseria, J. Chem. Phys. 131, 044108 (2009).

${ }^{34}$ V. Rassolov, J. Pople, M. Ratner, and T. Windus, J. Chem. Phys. 109, 1223 (1998).

${ }^{35}$ N. B. Balabanov and K. A. Peterson, J. Chem. Phys. 123, 064107 (2005).

${ }^{36}$ P. Rivero, I. d. P. R. Moreira, F. Illas, and G. E. Scuseria, J. Chem. Phys. 129, 184110 (2008).

${ }^{37}$ D. Stradi, C. Diaz, F. Martin, and M. Alcam, Theor. Chem. Acc. 128, 497.

${ }^{38}$ S. Gorelsky and A. Lever, J. Organomet. Chem. 635, 187 (2001).

${ }^{39}$ P. Ros and G. Schuit, Theor. Chim. Acta 4, 1 (1966).

${ }^{40}$ J. C. Green and P. Decleva, Coord. Chem. Rev. 249, 209 (2005).

${ }^{41}$ J. C. Green, Acc. Chem. Res. 27, 131 (1994).

${ }^{42} \mathrm{~J}$. Yeh, Atomic Calculation of Photoionization Cross-Sections and Asymmetry Parameters, edited by P. Langhorne (Gordon and Breach Science Publishers, 1993).

${ }^{43}$ J. Yeh and I. Lindau, At. Data Nucl. Data Tables 32, 1 (1985).

${ }^{44}$ J. Åhlund, K. Nilson, J. Schiessling, L. Kjeldgaard, S. Berner, C. Puglia, B. Brena, M. Nyberg, Y. Luo, and N. Mårtensson, J. Chem. Phys. 125, 34709 (2006).

${ }^{45}$ Y. Alfredsson, B. Brena, K. Nilson, J. Åhlund, and L. K. et al., J. Chem. Phys. 122, $214723(2005)$.

${ }^{46}$ E. Clementi and D. L. Raimondi, J. Chem. Phys. 38, 2686 (1963).

${ }^{47}$ F. Petraki, H. Peisert, P. Hoffmann, J. Uihlein, M. Knupfer, and T. Chass, J. of Phys. Chem. C 116, 51215127 (2012).

${ }^{48}$ B. E. Williamson, T. C. VanCott, M. E. Boyle, G. C. Misener, M. J. Stillman, and P. N. Schatz, J. Am. Chem. Soc. 114, 24122419 (1992). 
1) In detail comparison between the valence band electronic structure of $\mathrm{H}_{2} \mathrm{Pc}, \mathrm{FePc}$ and $\mathrm{MnPc}$;

2) Comparison between the gas phase samples and thin evaporated films on $\mathrm{Au}$;

3) Detailed analysis of the atomic orbital contributions (C 2p, N 2p and metal 3d) to the valence band features;

4) The analysis of the outer valence spectra of gas phase Pcs shows that the HOMO of $\mathrm{H}_{2} \mathrm{Pc}$ and FePc coincides in $\mathrm{BE}$ with the HOMO-1 peak of the MnPc spectra and is the result of excitations from an au orbital with mainly $\mathrm{C} 2 \mathrm{p}$ character. 


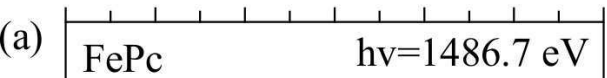

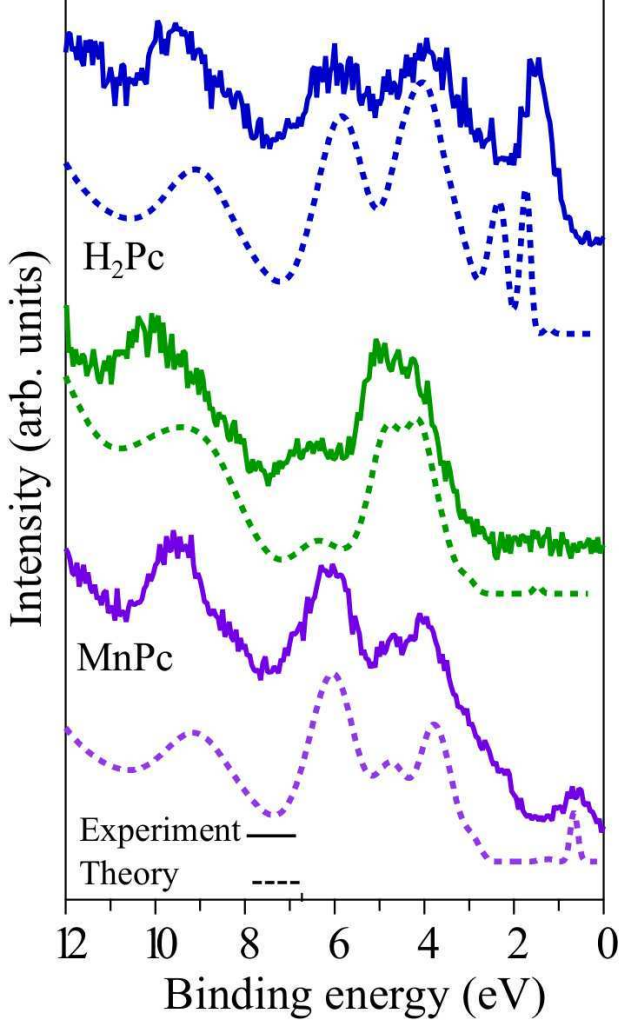

(b)

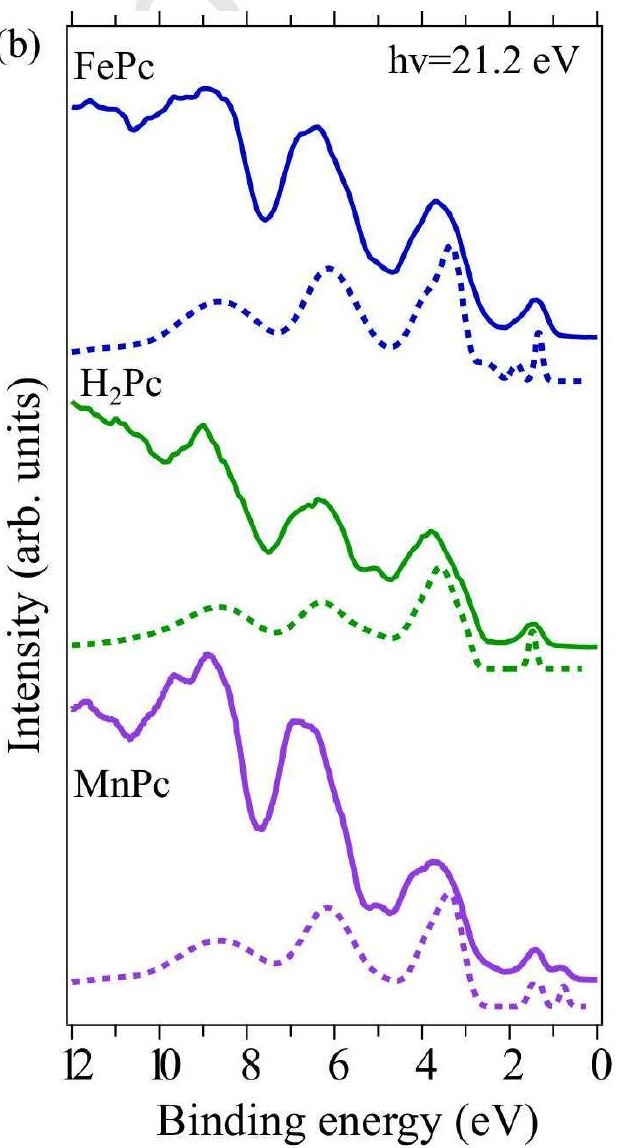

(c)

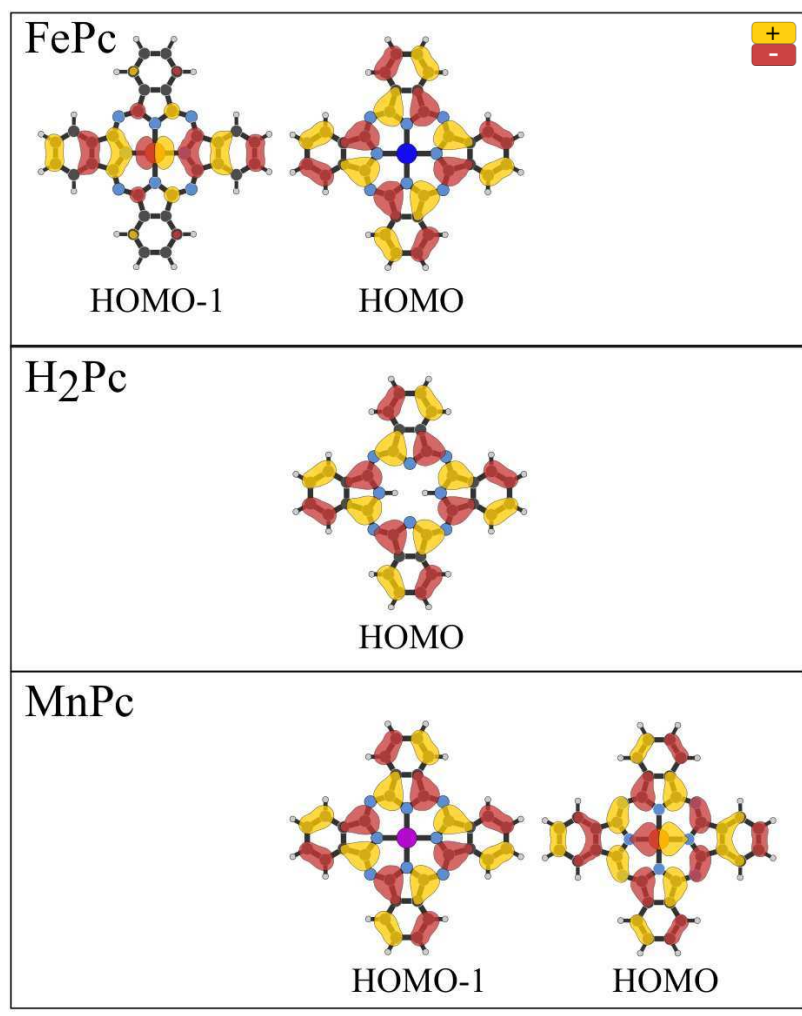




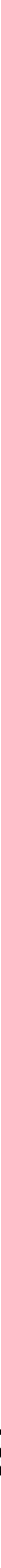

\section{Binding Energy (eV)}




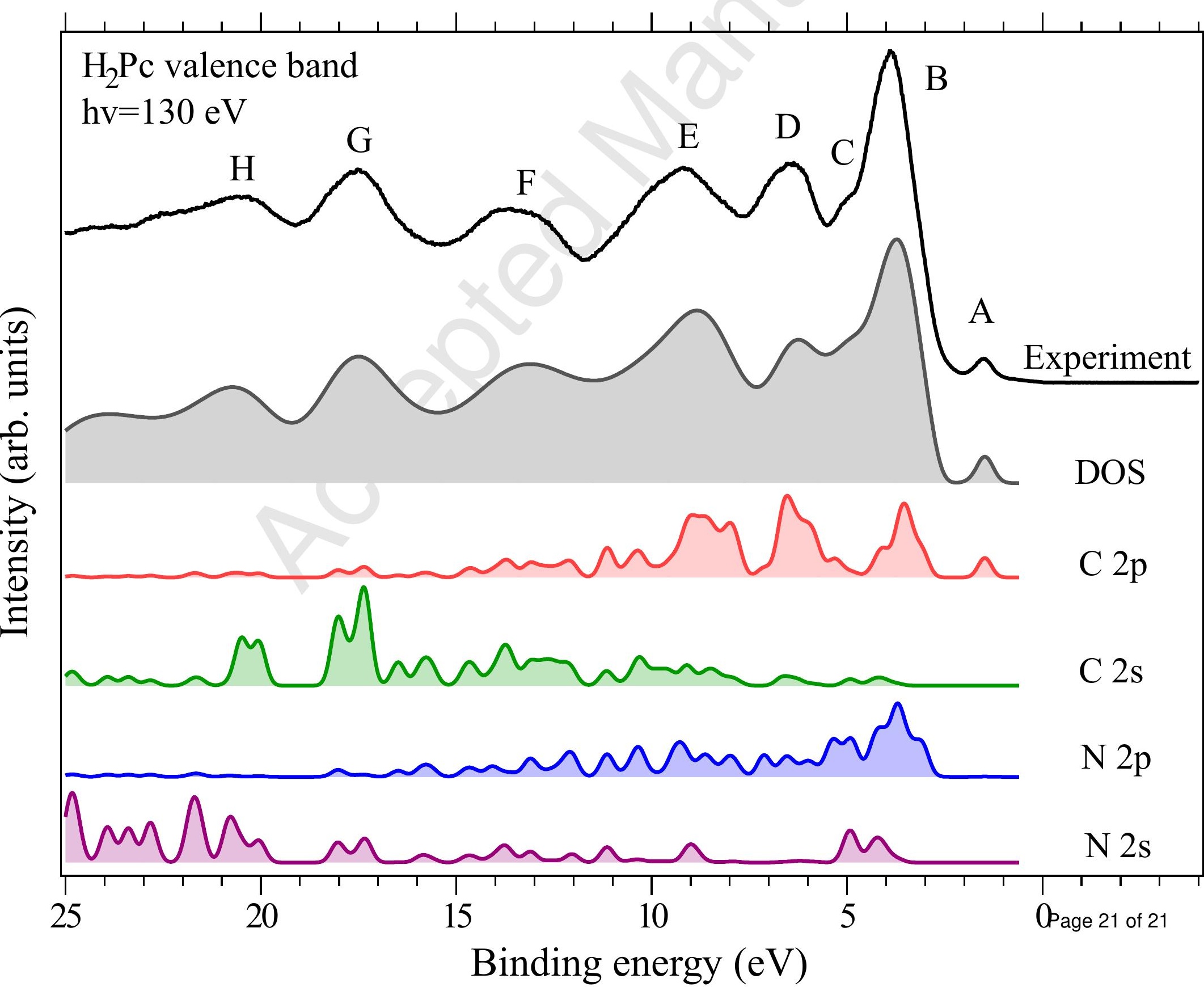

